\title{
Development of dehydrated pomegranate arils from unmarketable pomegranates and evaluation of their functional and organoleptic attributes during storage
}

\author{
N.S. Thakur, Shreya Kashyap, Abhimanyu Thakur, Anshu Sharma , Sunakshi Gautam and Hamid \\ Department of Food Science and Technology, Dr. Y. S. Parmar University of Horticulture and Forestry, Nauni, Solan-173230, Himachal Pradesh,
} India

\section{Article Info}

Article history

Received 1 October 2021

Revised 19 November 2021

Accepted 20 November 2021

Published Online 30 December 2021

Keywords
Arils
Dehydration
Functional
Packaging
Pomegranate
Unmarketable fruits

\begin{abstract}
Pomegranate fruit is rich source of anthocyanins, phenols, crude fibre, sugars, vitamins, minerals and antioxidants. It has become one of the commercial fruit of HP in recent years. However, sufficient amount of this crop goes waste because of fruit cracking. So, present research is focusing on the development of dried arils from the cracked/unmarketable fruits of Kandhari Kabuli cultivar of this fruit. The arils after manual extraction were steam blanched $(30$ to $90 \mathrm{sec})$ and best steam blanching time $(60 \mathrm{sec})$ was standardized to inactivate enzymes. Treated arils were then dipped in citric acid solution of varying concentrations for different time periods, followed by sulphur fumigation $(0.3 \%$ for $60 \mathrm{~min})$ and best treatment (dipping in $50 \%$ citric acid for $5 \mathrm{~min}$ ) was selected for dehydration under mechanical cabinet drier. Dehydrated arils were packed in four different packaging material including jute bags, polyethylene pouches (PEP), aluminium laminated pouches (ALP) and ALP with vacuum and stored under ambient (18$\left.27^{\circ} \mathrm{C}\right)$ and refrigerated $\left(4-7^{\circ} \mathrm{C}\right)$ temperature conditions for 6 months. Dehydrated arils packed in ALP with vacuum and stored under refrigerated conditions retained maximum concentrations of functional components such as vitamin $\mathrm{C}$, anthocyanins, total phenols, organic acids with overall better antioxidant potential and organoleptic attributes even after six months of storage in comparison to other treatments.
\end{abstract}

\section{Introduction}

Pomegranate (Punica granatum L.) belongs to family Punicaceae which is one of the most important fruit of tropical and sub-tropical regions of the world (Mir et al., 2012). The scientific name Punica granatum is derived from name Pomum (apple) and granatum (grainy) or seeded apple (Chandra et al., 2010). The fruit is native of Iran and is extensively cultivated in Spain, Egypt, Russia, France, Argentina, China, Japan, USA and India. India ranks first in pomegranate cultivation in the world (NHB, 2018). The production of this fruit in India during the year 2017-18 was 2845 thousand metric tons from an area of 234 thousand hectares (MAFW, 2018). It is commercially cultivated in Maharashtra, Gujarat, Rajasthan, Karnataka, Tamil Nadu, Andhra Pradesh, Uttar Pradesh, Punjab, Haryana and Himachal Pradesh (Patil and Karade, 1996). Among these states, Maharashtra accounts for 78 per cent of total cultivated area and 84 per cent production in the country (NHB, 2018). More than 90 per cent of the produce is utilized for fresh consumption as well as for export in international market, the countries like Spain (45\%) and Iran (15\%) are in competition with India (Dhumal et al., 2014). In HP, commercial pomegranate is mainly grown in sub-mountain areas of Kullu and Mandi, but nowadays, it is also grown in sub-tropical areas like Hamirpur, Bilaspur, Sirmour and Solan (Kumar et al., 2008). Its

Corresponding author: Dr. Anshu Sharma

Department of Food Science and Technology, Dr. Y. S. Parmar University of Horticulture and Forestry, Nauni, Solan-173230, Himachal Pradesh, India

E-mail: anshufst1989@gmail.com

Tel.: +91-8219884944

Copyright $(\odot) 2021$ Ukaaz Publications. All rights reserved.

Email: ukaaz@yahoo.com; Website: www.ukaazpublications.com production has been estimated as 3.15 thousand metric tonnes from an area of 2.77 thousand hectares in the state (MAFW, 2018).

Pomegranate fruits vary in colour from yellow, green or pink to bright deep red, depending on the cultivar and stage of ripening (Holland et al., 2009). Its fruit is a false berry, internally having multi ovule chambers separated by membranous walls and a fleshy mesocarp and chambers are filled with shiny red seeds enclosed in succulent and edible red pink pulp called arils. The colour of the arils varies from white to deep red depending upon the cultivar (Dhinesh and Ramasamy, 2016). The edible portion of pomegranate is an excellent source of multiple beneficial bioactive components like ascorbic acid, anthocyanins, gallic acid, ellagic acid, punicalagin, quercetin, etc., which prevent generation of various diseases (Thakur et al., 2019, Hamid et al., 2020a; Hamid et al., 2020b). The fruit is also rich source of anthocyanins, phenols, crude fibre and vitamins (Sreekumar et al., 2014). It is known as 'superfruit' and food medicine because of its high nutritive value, high antioxidant capacity, high potentially bioactive compounds, chemopreventive properties having medicinal value and high consumers appeal. Its fruit has got various medicinal properties including laxative, diuretic and used for curing, vomiting, sore throat, earaches, chest troubles, spleen complaints, bronchitis, liver and kidney disorders (Radha and Mathew, 2007). Excellent flavour, nutritive value and medicinal properties of pomegranate fruit indicate its good potentiality for processing into value added products (Dhumal et al., 2014).

In India, despite of the known nutraceuticals benefits and great global demand for pomegranate derived products, the pomegranate industry is not developed due to lack of technological developments for commercialization (Dhumal et al., 2014). Sound pomegranate fruits 
fetch a fairly good price in the market. However, low quality fruits such as cracked, damaged, spotted or small/under sized fruits fetch a low price or become unmarketable. One of the major problems in pomegranate cultivation is the cracking of its fruit at maturity which leads to huge economic loss to farmers. Kandhari Kabuli is one of the cultivar of this fruit which has got the cracking problem. Efforts have been made in the past to use these fruits for the production of anardana but the product prepared from the commercial cultivars contains very small amount of acid which does not fulfill the requirement as acidulants in various culinary purposes. So, the studies were carried out to develop mechanical cabinet dried arils with high acid content from unmarketable fruits of Kandhari Kabuli cultivar.

\section{Materials and Methods}

\subsection{Raw material}

Ripe fruits of Kandhari Kabuli cultivar of pomegranate (Figure 1) were procured from Bajaura district of Kullu (HP) and brought to Product Development Laboratory of Department of Food Science and Technology, UHF, Nauni, Solan (HP). The fruits were used for various physicochemical analysis and preparation of dried pomegranate arils.

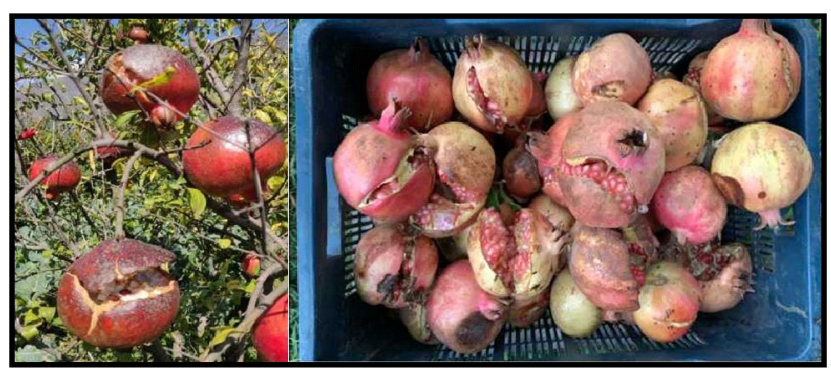

Figure 1: Commercial pomegranate fruits.

2.2 Optimization of pretreatments before mechanical cabinet dehydration

\subsubsection{Blanching time}

Arils were steam blanched for varying period of time and activity of peroxidase enzyme was observed.

\subsubsection{Impregnation of acid}

Blanched arils were dipped in different concentrations of citric acid for varying times. Various treatment combinations of citric acid concentration of $0 \%, 20 \%, 30 \%, 40 \%$ and $50 \%$ for different time intervals, i.e., 5, 10 and 15 min were given before dehydration.

\subsubsection{Preparation of anardana}

The drying of arils was carried out in mechanical cabinet drier (Figure 2). Anardana was prepared as per the method (Figure 3), suggested by Thakur et al. (2010). The pre-treated arils were thoroughly spread on perforated steel trays of dimension of $(76 \times 56 \mathrm{~cm})$ in mechanical cabinet drier. The temperature for drying was set at $60 \pm 2{ }^{\circ} \mathrm{C}$ and product was dried until it attained the constant weight.

\subsection{Packaging and storage}

The cabinet dried arils were packed in different packaging materials, i.e., jute bags, PEP, ALP and ALP with vacuum and further stored under room temperature conditions $\left(18-27^{\circ} \mathrm{C}\right)$ and refrigerated temperature $\left(4-7^{\circ} \mathrm{C}\right)$ conditions for a period of 6 months. Dried arils were analyzed for changes in functional and organoleptic attributes at different intervals ( 0 and 6 months) of storage.

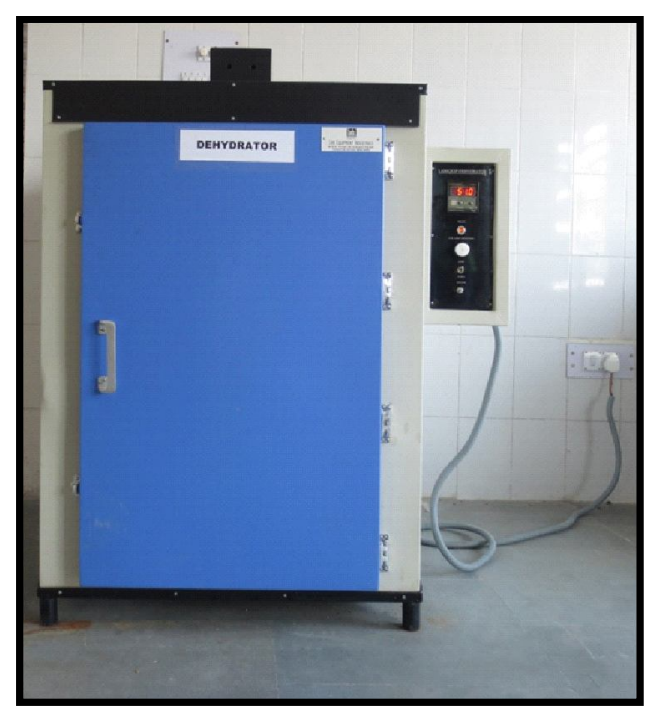

Figure 2: Mechanical cabinet drier.

\subsection{Chemical and organoleptic analysis}

Peroxidase activity was determined as per method explained by Putter (1974). Organic acid per cent in terms of titratable acidity, vitamin $\mathrm{C}$ and anthocyanin content were determined according to the procedures mentioned in Ranganna (2009). Total phenolic content was determined by Folin-Ciocalteu procedure given by Singleton and Rossi (1965). Free radical scavenging activity was measured as per the method of Brand-Williams et al. (1995). The organoleptic evaluation of the samples was carried out by 9 point hedonic rating test.

\subsection{Statistical analysis}

The data on chemical (functional) characteristics of dried arils were analyzed by completely randomized design (CRD factorial) whereas, data pertaining to the sensory (organoleptic) evaluation of dried wild pomegranate arils were analyzed by randomized block design (RBD). The data on chemical and sensory characteristics of dried arils were replicated three times.

\section{Results}

3.1 Optimization of pre-treatments for the development of dehydrated pomegranate arils

\subsubsection{Effect of blanching}

Data appended in Figure 4 depict the enzymatic activity of peroxidase enzyme in arils. The assessment of data indicates that as the blanching time increased, the enzyme activity decreased subsequently. Considerable leaching of visual colour pigments also increased with the increase in blanching time up to $60 \mathrm{sec}$, thereafter not much decrease in colour of arils was observed. So, pre-treatment of arils with steam blanching for $60 \mathrm{sec}$ was standardized based on the estimation of optimum enzyme activity of 0.624 units $/ \mathrm{min} / \mathrm{g}$ fresh weight. 


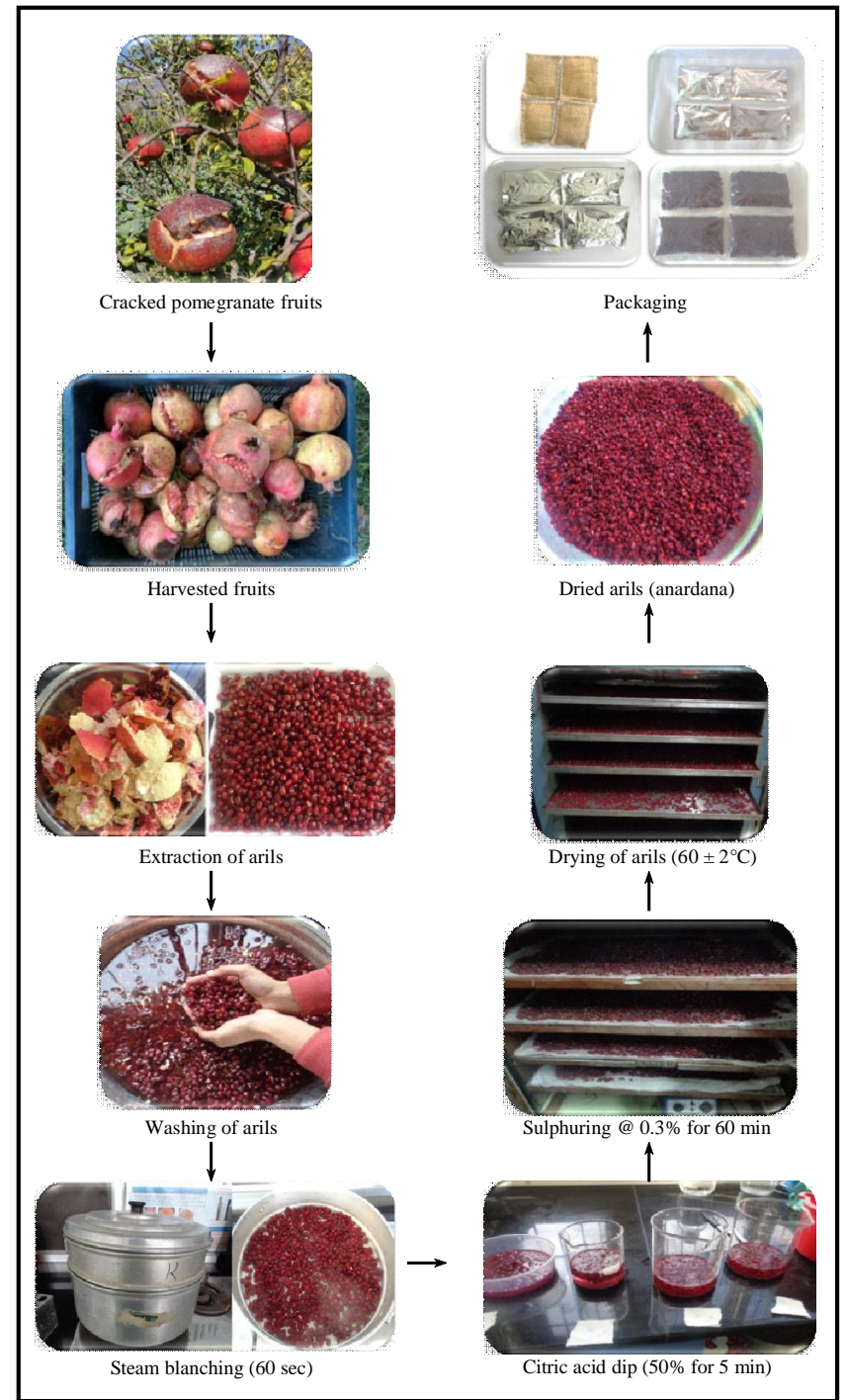

Figure 3: Unit operations for the preparation of anardana from commercial pomegranate.

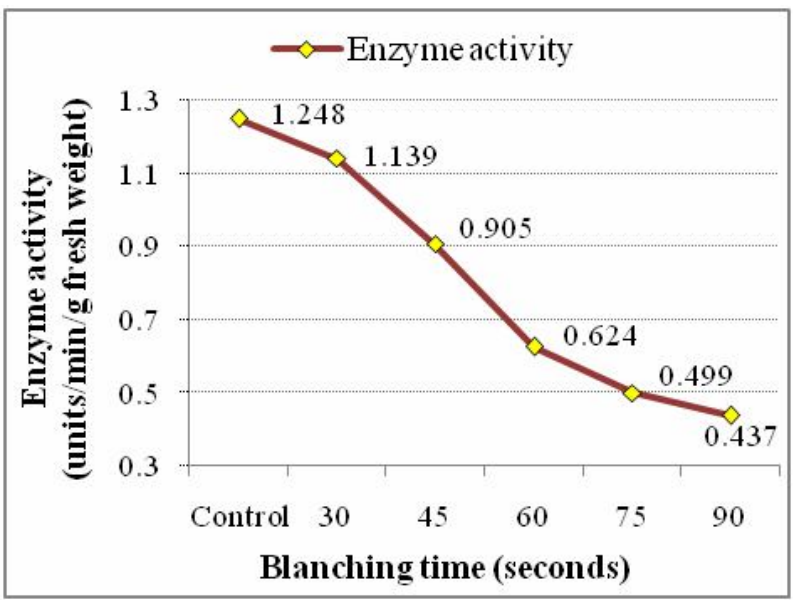

Figure 4: Effect of blanching time on enzyme activity of fresh arils of pomegranate.

\subsubsection{Effect of impregnation of organic acid}

Steam blanched arils were then further dipped in various concentrations of citric acid solution for different time period and the data on the effect of dipping arils of unmarketable pomegranates in different concentrations of citric acid (\%) with the varying time period ( $\mathrm{min}$ ) on the organoleptic quality attributes of dehydrated arils (anardana) is depicted in Table 1 . Out of all the given pretreatments, $\mathrm{T}_{14}(50 \%$ citric acid for $5 \mathrm{~min}$ ) with highest score of 7.28 for colour, 7.30 for texture, 8.70 for flavour and 8.75 for overall acceptability on the basis of organoleptic evaluation was selected as an optimized pretreatment.

Table 1: Effect of pre-treatments on the organoleptic characteristics of dehydrated pomegranate arils

\begin{tabular}{|l|c|c|c|c|}
\hline Treatments & Colour & Texture & Flavour & $\begin{array}{c}\text { Overall } \\
\text { acceptability }\end{array}$ \\
\hline $\mathrm{T}_{1}:$ Control & 7.35 & 7.20 & 6.00 & 6.00 \\
$\mathrm{~T}_{2}: 20 \%$ Citric acid for $5 \mathrm{~min}$ & 7.25 & 7.10 & 6.90 & 7.15 \\
$\mathrm{~T}_{3}: 20 \%$ Citric acid for $10 \mathrm{~min}$ & 7.00 & 7.00 & 7.50 & 7.20 \\
$\mathrm{~T}_{4}: 20 \%$ Citric acid for $15 \mathrm{~min}$ & 6.95 & 7.10 & 6.80 & 6.70 \\
$\mathrm{~T}_{5}: 25 \%$ Citric acid for $5 \mathrm{~min}$ & 7.20 & 7.20 & 6.70 & 6.90 \\
$\mathrm{~T}_{6}: 25 \%$ Citric acid for $10 \mathrm{~min}$ & 7.12 & 7.11 & 6.90 & 7.00 \\
$\mathrm{~T}_{7}: 25 \%$ Citric acid for $15 \mathrm{~min}$ & 6.89 & 7.12 & 6.90 & 6.88 \\
$\mathrm{~T}_{8}: 30 \%$ Citric acid for $5 \mathrm{~min}$ & 7.20 & 7.00 & 6.80 & 7.50 \\
$\mathrm{~T}_{9}: 30 \%$ Citric acid for $10 \mathrm{~min}$ & 7.10 & 7.20 & 7.10 & 7.00 \\
$\mathrm{~T}_{10}: 30 \%$ Citric acid for $15 \mathrm{~min}$ & 6.90 & 7.11 & 6.85 & 6.90 \\
$\mathrm{~T}_{11}: 40 \%$ Citric acid for $5 \mathrm{~min}$ & 7.25 & 7.12 & 7.30 & 7.25 \\
$\mathrm{~T}_{12}: 40 \%$ Citric acid for $10 \mathrm{~min}$ & 7.15 & 7.00 & 7.50 & 7.50 \\
$\mathrm{~T}_{13}: 40 \%$ Citric acid for $15 \mathrm{~min}$ & 6.85 & 7.10 & 7.75 & 7.90 \\
$\mathrm{~T}_{14}: 50 \%$ Citric acid for $5 \mathrm{~min}$ & 7.28 & 7.30 & 8.70 & 8.75 \\
$\mathrm{~T}_{15}: 50 \%$ Citric acid for $10 \mathrm{~min}$ & 7.10 & 7.00 & 8.45 & 8.65 \\
$\mathrm{~T}_{16}: 50 \%$ Citric acid for $15 \mathrm{~min}$ & 6.75 & 7.20 & 8.40 & 8.60 \\
\hline $\mathbf{C D}_{0} 0.05$ & $\mathbf{N S}$ & $\mathbf{N S}$ & $\mathbf{0 . 2 8}$ & $\mathbf{0 . 2 6}$ \\
\hline
\end{tabular}

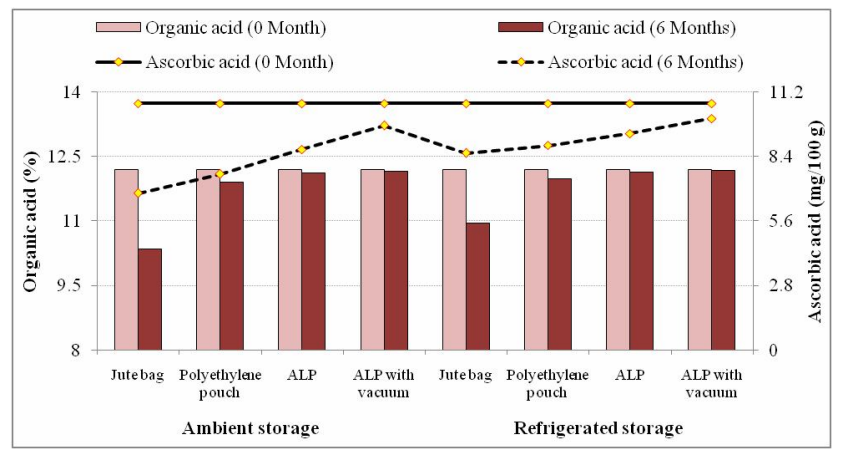

Figure 5: Effect of packaging on organic acid (\%) and vitamin $\mathrm{C}(\mathrm{mg} / 100 \mathrm{~g})$ of dehydrated arils during storage.

3.2 Effect of packaging treatments on functional attributes of dehydrated pomegranate arils during storage

\subsubsection{Organic acid and vitamin $C$ content}

An appraisal of data (Figure 5) reveal that there was a minor decreasing trend in organic acid content and significant decrease in 
vitamin $\mathrm{C}$ of dehydrated pomegranate arils during entire storage period of 6 months. Further, while comparing the overall effect of storage conditions, it was found that maximum organic acid per cent $(12.00 \%)$ and vitamin C $(9.97 \mathrm{mg} / 100 \mathrm{~g})$ was retained under refrigerated storage conditions as compared to room temperature conditions. The overall effect of packaging materials indicates that maximum $(12.18 \%)$ acidity and vitamin C $(10.31 \mathrm{mg} / 100 \mathrm{~g})$ were retained in ALP with vacuum packaging treatment during storage.

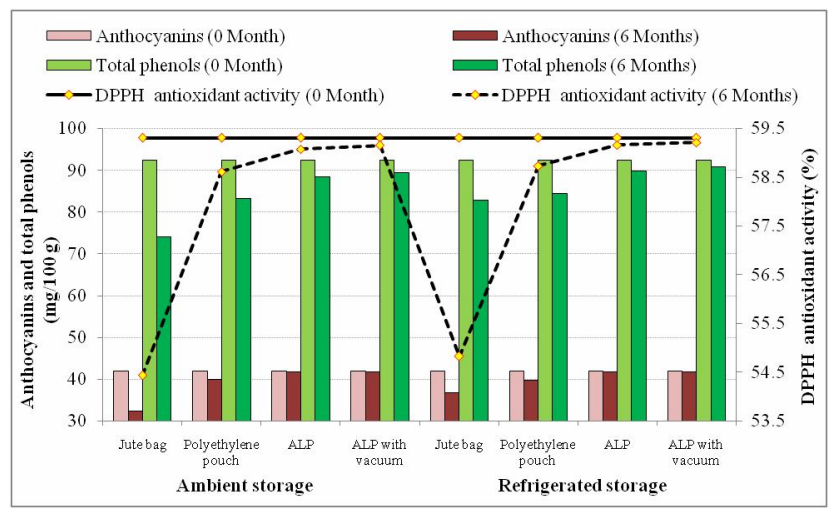

Figure 6: Effect of packaging on anthocyanins $(\mathrm{mg} / 100 \mathrm{~g})$, total phenols (mg/100 g) and DPPH antioxidant activity (\%) of dehydrated arils during storage.

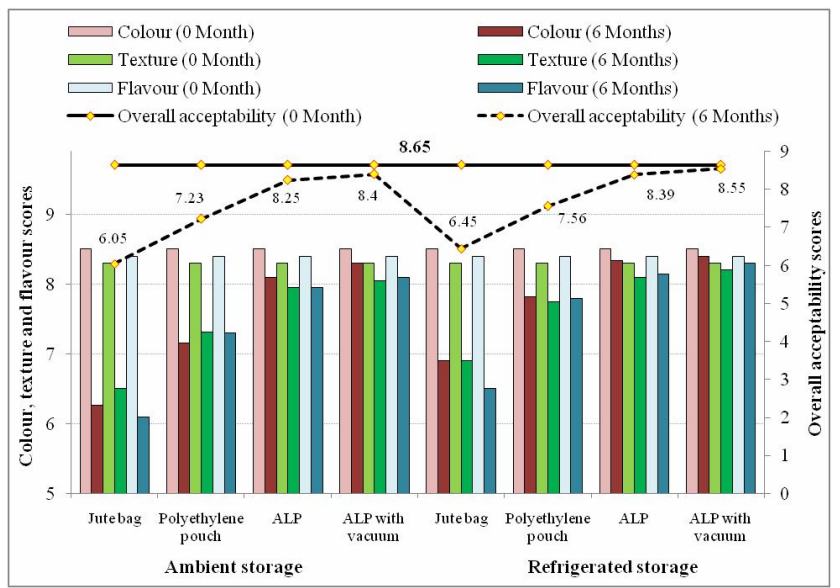

Figure 7: Effect of packaging on sensory characteristics of dehydrated arils during storage.

\subsubsection{Anthocyanins, total phenolics and antioxidant activity}

Data presented in Figure 6 depict that during entire storage, there was a general decreasing trend in anthocyanins and phenolic content of dried arils. While comparing the overall effect of storage conditions, it was found that maximum anthocyanins $(41.78 \mathrm{mg} / 100 \mathrm{~g})$ and phenolics $(91.21 \mathrm{mg} / 100 \mathrm{~g})$ were retained under refrigerated storage conditions in ALP packaging with vacuum conditions. An assessment of data in Figure 6 revealed that the DPPH antioxidant activity of dehydrated arils decreased notably during entire storage period. The lower $(58.56 \%)$ and higher $(58.64 \%)$ antioxidant activities were found in dehydrated arils stored under ambient and refrigerated storage conditions, respectively. The overall effect of packaging material reveals that maximum $(58.68 \%)$ antioxidant activity of dehydrated arils was found in ALP with vacuum and lowest in jute bag (57.04\%).

\subsubsection{Organoleptic characteristics}

Figure 7 illustrates a general decrease in organoleptic scores of dehydrated arils was observed during storage. While comparing overall effect of storage conditions and packaging treatments, it was observed that colour, texture, flavour and overall acceptability scores were retained higher $(8.42,8.20,8.30,8.55)$ in aluminum laminated pouches with vacuum under refrigerated storage conditions as compared to other packaging treatments and ambient conditions.

\section{Discussion}

4.1 Optimization of pretreatments for the development of dehydrated pomegranate arils

Enzyme activity was reduced at higher rate up to $60 \mathrm{sec}$ of blanching; thereafter, it decreased at reduced rate. The reason behind this might be that when the sample exposed to steam blanching for 30 to 60 seconds, the enzyme worked efficiently. This is due to the biphasic nature of peroxidase enzyme, which has both heat labile and heat resistant fractions. Due to more exposure time of enzyme to high temperature, sensitive fractions occurred which reduced the enzymatic activity of the sample. Same findings were recorded by Bhat et al. (2019) on the peroxidase activity in bottle gourd after blanching. The colour scores decreased insignificantly with decrease in dipping time and acid concentration. The reason behind this might be due to the retention of colour pigments as a result of reduced $\mathrm{pH}$ because of incorporation of acid in arils (Chaethong and Pongsawatmanit, 2015). However, with the passage of dipping time and increase in acid concentrations, colour intensity decreased in the end product as a result judges awarded lower scores to the subsequent treatments. Among all the treatments, the highest score of organoleptic attributes recorded in $\mathrm{T}_{14}$ might be due to the excellent sugar acid blend as compared to the other pre-treatments.

4.2 Effect of packaging treatments on functional attributes of dehydrated pomegranate arils during storage

\subsubsection{Organic acid and vitamin $C$ content}

Slight decrease in the organic acid per cent of dehydrated pomegranate arils were observed which might be due to the chemical reactions between sugars and amino acids for the formation of NEB products and HMF, as well as utilization in the inversion of non-reducing sugars to reducing sugars. Dehydrated arils showed a significant decrease in vitamin $\mathrm{C}$ during the entire storage period which might be due to its oxidation and direct effect of ambient storage conditions on vitamin (Clegg and Mortar, 1965). Maximum acidity and vitamin $\mathrm{C}$ of dried arils was retained under refrigerated storage conditions as compared to ambient which might be due to the slower rate of chemical reactions and oxidation as a result of low temperature. The anardana packed in ALP with vacuum have retained maximum acid and vitamin $\mathrm{C}$ content which might be due to the vacuum conditions inside the pouch which restricted the involvement of acids and restricted oxidation of vitamin $\mathrm{C}$ in absence of air. Same trend of decrease in organic acid and vitamin $\mathrm{C}$ content of dried arils during storage have also been reported by Singh and Kingsley (2008), Sharma et al., (2013), Bhat et al. (2014), Sharma and Thakur (2016) and Thakur et al. (2020a). Thakur et al. (2020b) have reported the least losses of organic acid and vitamin $\mathrm{C}$ content in mechanical cabinet dried wild pomegranate arils packed in ALP with vacuum and ALP as compared to gunny bag. 


\subsubsection{Anthocyanins, total phenolics and antioxidant activity}

Due to the susceptible nature towards oxidative losses caused by air, moisture, temperature, light and hydrolytic degradation of bioactive components lead to a significant decrease in anthocyanins and total phenols of dried arils during storage. Product stored under refrigerated temperature conditions retained more anthocyanins and total phenols as a result of slower rate of oxidation reactions under low temperature conditions. ALP with vacuum retained more anthocyanins and total phenols of anardana as compared to others. This might be due to the opaqueness of aluminium foil in the ALP to light and permeability of the packaging material to oxygen, water vapours and vacuum inside the pouch that checked oxidation of anthocyanins and total phenols. Total phenol content of the bael powder decreased with increase in storage period and the level of decrease was slightly lesser in the powder stored at low temperature as compared to room temperature which might have caused degradation of some unstable phenolic compounds due to the oxidation of oxygen during storage (Sagar and Kumar, 2014). The decrease in total phenol content of anardana during storage has also been observed by Bhat et al. (2014), Sharma and Thakur (2016) and Thakur et al. (2020c). Further, they have observed the minimum losses of total phenols in anardana in ALP under refrigerated storage conditions as compared to PEP, thermoform tray and gunny bag. Dak et al. (2014) have also observed minimum loss in anthocyanins content of anardana prepared from Maridula cultivar of pomegranate packed in ALP under ambient storage conditions. The decrease in anthocyanin content of anardana during storage has also been observed by Bhat et al. (2014), Sharma and Thakur (2016) and Thakur et al. (2020c). Further, they have observed the minimum losses of anthocyanins in anardana in ALP and ALP with vacuum under refrigerated storage conditions.

During storage period of 6 months DPPH antioxidant activity of dehydrated arils decreased significantly which might be due to the degradation of chemical characteristics like ascorbic acid, total phenols and anthocyanins and other reason could be the non-enzymatic browning reactions (Melgarejo-Sanchez et al., 2015). The loss of antioxidant activity was lower in the dehydrated arils stored under refrigerated temperature conditions as compared to ambient which might be due to the slower rates of degradation of various antioxidant compounds present in the product which helped in the retention of higher antioxidant activity. Product packed in ALP with vacuum retained maximum antioxidant activity which might be due to the favorable conditions inside the pouch which created barrier to light, air and moisture, therefore, prevented degradation of various antioxidant compounds. Thakur et al. (2020c) and Thakur et al. (2021) have also reported a decrease in antioxidant activity in solar and mechanical cabinet dried wild pomegranate arils dried arils during 12 months of storage period.

\subsubsection{Organoleptic characteristics}

The sensory scores of dehydrated arils exhibited significant decrease during storage which might be due to the loss of natural colour pigments, organic acids, vitamin $\mathrm{C}$ as a result of which judges awarded the lower scores to the product as compared to inceptive scores. Other reason could be the development of browning pigments due to non-enzymatic browning reactions and oxidation which distorted the colour and flavor of the product. Maximum sensory scores retained under refrigerated storage might be due to the better retention of colour and flavor of the product as a result of the suitable storage conditions where the rate of degradation of bioactive components were slower as compared to ambient storage conditions. However, maximum retention of scores of dehydrated arils in ALP with vacuum might be due to the better retention of these scores as a result of favorable conditions inside the pouch which created a barrier to light, air and moisture, therefore prevented deterioration of many functional components, thus led the judges to award the better scores as compared to other packaging material. Similar trend of decrease in organoleptic scores have also been observed by Grande et al. (2004) in anardana from Ganesh cultivar packed in polyethylene pouch stored under ambient temperature conditions, Bhat et al. (2014) in anardana packed in ALP under ambient and refrigerated temperature conditions and Sharma and Thakur (2016) in anardana in ALP and PEP stored under ambient temperature conditions.

\section{Conclusion}

Anardana (dried arils) is a commercial product which is mainly prepared from wild pomegranate, but it can also be prepared from healthy or cracked fruits of commercial pomegranate cultivar (Kandhari Kabuli) by increasing its acid content in suitable amount. For developing the best quality anardana (dried arils) its arils can first be steam blanched for $60 \mathrm{sec}$, then dipped in 50 per cent citric acid solution for $5 \mathrm{~min}$, followed by sulphuring @ 0.3 per cent for 60 min before drying. Best pre-treated arils can be dried in mechanical cabinet drier successfully at $60 \pm 2{ }^{\circ} \mathrm{C}$ for the development of dehydrated arils. Mechanical cabinet dried arils (anardana) packed in aluminium laminated pouch (ALP) with vacuum stored under refrigerated conditions retained better functional and organoleptic during 6 months of storage. Conclusively, these results can provide a supplementary benefit to the pomegranate growers, if this technology is followed efficiently.

\section{Conflict of interest}

The authors declare no conflicts of interest relevant to this article.

\section{References}

Bhat, M.M.; Thakur, N.S. and Jindal, N. (2014). Studies on the effect of drying methods and packaging on quality and shelf life of dried wild pomegranate arils. Asian Journal of Dairy and Food Research, 33:18-24.

Bhat, S.; Saini, C.S.; Kumar, M. and Sharma, H.K.(2019). Peroxidase as indicator enzyme of blanching in bottle gourd (Lagenaria siceraria): Changes in enzyme activity, colour and morphological properties during blanching. Journal of Food Processing and Preservation DOI: $10.1111 /$ jfpp. 14017

Brand-Williams, W.; Cuvelier, M.E. and Berset, C. (1995). Use of free radical method to evaluate antioxidant activity. Lebensmittel-Wissenschaft and Technology, 28:25-30.

Chaethong, K. and Pongsawatmanit, R. (2015). Influence of sodium metabisulfite and citric acid in soaking process after blanching on quality and storage stability of dried chilli. Journal of Food Processing and Preservation, 39:2161-2170.

Chandra, R.; Jadhav, V.T. and Sharma, J. (2010). Global scenario of pomegranate (Punica granatum L.) culture with special reference to India. Fruit, Vegetable and Cereal Science and Biotechnology, 2:7-18.

Clegg, R.M. and Mortar, A.D. (1965). Carbonyl compounds and non-enzymatic browning of lemon juice. Journal of the Science of Food and Agriculture, 16:191-192. 
Dak, M.; Sagar, V.R. and Jha, S.K. (2014). Shelf-life and kinetics of quality change of dried pomegranate arils in flexible packaging. Food Packaging and Shelf Life, 2:1-6.

Dhinesh, K.V. and Ramasamy, D. (2016). Pomegranate processing and value addition: Review. Journal of Food Processing and Technology, 7:565568

Dhumal, S.S.; Karale, A.R.; Jadhav, S.B. and Kad, V.P. (2014). Recent advances and the developments in the pomegranate processing and utilization: A review. Journal of Agriculture and Crop Science, 1:1-17.

Grande, V.K.; Masalkar, S.D.; Gaikand, R.S. and Patil, R.S. (2004). Studies on preparation and storage of anardana. Agriculture Science Digest, 24:283-285.

Hamid.; Thakur, N.S. and Thakur, A. (2020a). Microencapsulation of wild pomegranate flavedo phenolics by lyophilization: Effect of maltodextrin concentration, structural morphology, functional properties, elemental composition and ingredient for development of functional beverage. LWT-Food Science and Technology, 133:1 10077 https://doi.org/10.1016/j.lwt.2020.110077

Hamid.; Thakur, N.S.; Thakur, A.; Sharma, C.; Bhatt, K. and Khan, A.A. (2020b) Pomegranate and its wild genotypes: Nutraceutical opportunities and challenges. Ann. Phytomed., 9:32-43 http://dx.doi.org/ 10.21276/ap.2020.9.1.5

Holland, D.; Hatib, K. and Bar, Y.I. (2009). Pomegranate: Botany, Horticulture and Breeding. In: Horticultural Reviews. Jules, J. (ed.). Israel, John, Wiley and Sons. pp:130.

Kumar, J.; Khosla, K. and Sharma, J.P. (2008). Anar Utpad anavom Sanrakshan RHRS. Bajaura.

MAFW. (2018). Horticultural statistics at a glance 2018. www.agricoop. nic.in.

Melgarejo-Sanchez, P.; Martinez, J.J.; Legua, P.; Martinez, R.; Hernandez, F. and Melgarejo, P. (2015). Quality, antioxidant activity and total phenols of six Spanish pomegranates clones. Scientia Horticulturae, 182:6572 .

Mir, M.M.; Umar, S.A.; Mir, S.A.; Rehman, M.U.; Rather, G.H. and Bandy (2012) Quality evaluation of pomegranate crop: A review. International Journal of Agriculture and Biology, 14:658-667.

NHB. (2018). Area and production estimates of fruit crops for 2017 2018. http://www.nhb.gov.in.

Patil, A.V. and Karade, A.R. (1996). Pomegranate. In: Fruits: Tropical and subtropical (Bose, T.K. and Mitra, S.K. (eds). Naya Prakash, Calcutta. pp:614-631.

Putter, J. (1974). In: Methods of Enzymatic Analysis 2 (Ed. Bergmeyer, A.). Academic Press, New York, pp:685

Radha, T. and Mathew, L. (2007). Pomegranate In: Fruit crops (Peter, K.V.eds). New India Publishing Agency, Pritam Pura, New Delhi. pp:276-284.
Ranganna, S. (2009). Handbook of Analysis and Quality Control for Fruit and Vegetable Products. Tata McGraw Hill, New Delhi, pp:1112.

Sagar, V.R. and Kumar, R. (2014). Effect of drying treatments and storage stability on quality characteristics of bael powder. Journal of Food Science and Technology, 9:2162-2168.

Sharma, A. and Thakur, N.S. (2016). Influence of active packaging on quality attributes of dried wild pomegranate (Punica granatum L.) arils during storage. Journal of Applied and Natural Science, 8:398-404.

Sharma, S.R.; Bhatia, S.; Arora, S.; Mittal, T.C. and Gupta, S.K. (2013). Effect of storage conditions and packaging material on quality of anardana. International Journal of Advances in Engineering and Technology, 6:2179-2186.

Singh, D.B. and Kingsly, A.R.P. (2008). Effect of convective drying on quality of anardana. Indian Journal of Horticulture, 65:413-416.

Singleton, V.L. and Rossi, J.A. (1965). Colorimetry of total phenolics with phosphomolybedicphosphotungstic acid reagents. American Journal of Enology and Viticulture, 16:144-58.

Sreekumar, S.; Sithul, H.; Muraleedharan, P. and Azeez, J. (2014). Pomegranate fruit as a rich source of biologically active compounds. Biomed Research International, 10:2-12.

Thakur, N.S.; Bhat, M.M.; Rana, N. and Joshi, V.K. (2010). Standardization of pretreatments for the preparation of dried arils from wild pomegranate. Journal of Food Science and Technology, 47:620-625

Thakur, A.; Joshi, V.K. and Thakur, N.S. (2019). Immunology and its relation with food components: An overview. International Journal of Food and Fermentation Technology, 9:1-16. https://www.doi.org/ 10.30954/2277-9396.01.2019.3

Thakur, A.; Thakur, N.S.; Hamid.; Kumar, P. and Bhatt, K. (2020a). Effect of packaging and storage on quality characteristics of dried wild pomegranate arils (anardana) prepared in solar tunnel drier. Current Journal of Applied Science and Technology, 39:8-23. https://doi.org/ 10.9734/CJAST/2020/v39i1330674

Thakur, A.; Thakur, N.S.; Hamid.; Kumar, P. and Bhatt, K. (2020b). Studies on storage quality evaluation of dried wild pomegranate arils (anardana) prepared in mechanical cabinet drier. International Research Journal of Pure and Applied Chemistry, 21:79-91. https://doi.org/10.9734/ IRJPAC/2020/v21i1130226

Thakur, A.; Thakur, N.S.; Hamid. and Gautam, S. (2020c). Effect of packaging on phenols, flavonoids and antioxidant activity of dried wild pomegranate (Punica granatum L.) arils prepared in solar tunnel drier. Ann. Phytomed., 9:197-205. http://dx.doi.org/10.21276/ ap.2020.9.2.17

Thakur, A.; Thakur, N.S.; Hamid. and Gautam, S. (2021). Effect of packaging on phenols, flavonoids and antioxidant characteristics of mechanical cabinet dried wild pomegranate (Punica granatum L.) arils. Journal of Applied and Natural Science, 13:101-109. https://doi.org/ 10.31018/jans.v13i1.2456

N.S. Thakur, Shreya Kashyap, Abhimanyu Thakur, Anshu Sharma, Sunakshi Gautam and Hamid (2021). 